\title{
Comunicación política: aproximación a la construcción de identidad ciudadana de los pequeños campesinos de Corrientes*
}

\author{
Leticia Quintana Pujalte*
}

\section{Resumen}

A partir de los aportes de sociólogos, filósofos y comunicadores, construimos la categoría de identidad ciudadana. Con esta categoría, estudiamos críticamente los discursos políticos mediatizados y no mediatizados (entrevistas) de pequeños campesinos de Corrientes, nucleados en asociaciones civiles que les brindan institucionalidad. Sus prácticas y discursos son enfocados para indagar respecto de la autodefinición del grupo y asociarla con los estudios sobre construcción de ciudadanía, participación e identidad. A partir de esta aproximación, consideramos las prácticas de resistencia de este grupo considerado vulnerable en las dimensiones social, política y, fundamentalmente, comunicacional.

\section{Palabras clave}

Ciudadanía - comunicación - identidad - campesinos.

\section{Abstract}

From sociologists, philosophers and journalists contributions, we arrive to the civic identity category. With this category, we study political discourse of small farmers in Corrientes, those

\footnotetext{
* Artículo recibido el 31 de mayo de 2013. Aceptado el 26 de agosto de 2013.

* Leticia Quintana Pujalte es Licenciada en Comunicación Social por la Universidad Nacional del Nordeste. Becaria Iniciaciación, Secretaría General de Ciencia y Técnica-UNNE.
} 
mediated and unmediated (interviews) discourses from a critical analysis. Their practices and discourses are focused to investigate about group self-definition and associate it with studies on citizenship, participation and identity construction. From this approach, we consider the practices of resistance in this group considered vulnerable in the social, political and, most importantly, communication aspect.

\section{Keywords}

Citizenship - communication - identity - farmers.

La comunicación política, rama particular de los estudios en comunicación, se enriquece de líneas teóricas aparentemente tan distantes como el estudio de la opinión pública, el análisis crítico del discurso, la filosofía política, la sociología política, los estudios del framing y de agenda-setting y el análisis de contenido. Estas técnicas de investigación y teorías nos ayudan a aproximarnos a un objeto complejo, como es el la construcción de identidades a partir del discurso político, su presencia e influencia en el espacio público en una sociedad de un tiempo y en un espacio determinados.

Siguiendo a Verón (1987), entendemos al discurso político como una lucha entre enunciados, es decir que en todo discurso considerado político, existe una fuerte dimensión polémica. En este sentido, la indagación que presentamos en este artículo pretende identificar en los enunciados aquellas marcas que establecen tanto a los adversarios como a los modelos ideales del "nosotros" del enunciador. Este "nosotros" entendido como generador de identidad a partir de la palabra, crucial para el ejercicio de la resistencia del grupo en cuestión: los pequeños campesinos de Corrientes.

Tomamos a Arendt (1993) en articulación con otros autores, y consideramos la tríada acción-discurso-identidad para estudiar las prácticas, discursos e identidad de los campesinos en relación con la participación política y su relación con el ejercicio de la resistencia y ciudadanía.

La filósofa alemana señala que uno de los rasgos de la condición humana es que "con palabra y acto nos insertamos en el mundo humano" (p. 201), e indica también que "el discurso corresponde al hecho de la distinción, y es la realización de la condición humana de la pluralidad, es decir, de vivir como ser distinto y único entre iguales" (p. 202). Propone además que mediante la acción y el discurso "los hombres se diferencian en vez de ser meramente distintos" (Arendt, 1993: 200).

Las citas son cruciales para comprender el proceso intelectual que nos llevó a proponer la articulación teórica que desarrollaremos a continuación y su relación con la construcción de una identidad particular, ya que consideramos que nos ocupamos de un tipo de identidad diferenciada de la línea tradicional inaugurada por T. H. Marshall, la identidad ciudadana. 
En Arendt (1993), acción y discurso, en tanto rasgos de la condición humana, tienen implicancias directas en la construcción de identidad, ya que

Mediante la acción y el discurso, los hombres muestran quiénes son, revelan activamente su única y personal identidad y hacen su aparición en el mundo humano (...). El descubrimiento de 'quien' en contraposición de 'qué' es alguien (...) está implícito en todo lo que ese alguien dice y hace". (Arendt, 1993: 203)

La capacidad de acción y de representación simbólica a través del discurso indica, entonces, un modo de construir la identidad a partir de la presencia y diferencia de y con los otros que permiten establecer la diferencia. Si pensamos en términos pragmáticos, esto tiene que ver con autodenominarse como un "yo" frente a un "tú", al que se apela (Benveniste, 1979), a partir de la enunciación. Entendemos que la construcción de la identidad está también vinculada con la capacidad de autodefinirse a partir de esquemas ideológicos colectivos compartidos, que se manifiestan a través del discurso y son producto de una serie de complejas relaciones entre sociedadcognición-discurso (Van Dijk, 1999).

Las líneas sucintamente mencionadas conforman los pilares para indagar acerca de la construcción de un tipo de identidad particular, la identidad ciudadana, de un grupo considerado vulnerable en su dimensión económica, política y -fundamentalmente para nuestro enfoque- comunicacional (López, 2009a y 2009b), como son los pequeños productores agropecuarios de Corrientes, agrupados en asociaciones no gubernamentales que les otorgan cierta institucionalidad.

Los objetivos del presente artículo son (a) indagar la vinculación entre construcción de ciudadanía, comunicación y política, desde estudios latinoamericanos y europeos; (b) establecer una relación entre estos estudios y los de construcción identitaria; (c) generar a partir de esta articulación la categoría de identidad ciudadana y (d) indagar huellas de esta construcción en los discursos de (y sobre) los campesinos.

Para indagar en el proceso de construcción identitaria con bases ciudadanas, estudiamos los discursos mediatizados de los dirigentes de organizaciones civiles campesinas de Corrientes, en un periódico de carácter alternativo como es Acción, del Instituto de Cultura Popular, desde la perspectiva del análisis crítico del discurso (Van Dijk, 1999, Wodak, 2003). A su vez, también realizamos entrevistas semiestructuradas con algunos de estos referentes rurales, específicamente de la Asociación Provincial de Pequeños Productores de Corrientes y de la Asociación Provincial de Ferias Francas de Corrientes; este último corpus nos permite analizar los discursos no mediatizados de estos actores.

\section{Estudios sobre ciudadanía}

El estudio del proceso de construcción de ciudadanía y su análisis requieren el pensamiento complejo y el compromiso de quien investiga, ya que imponen develar 
mitos naturalizados respecto de su ejercicio. Cuando nos adentramos en el proceso de interpelación de ese mito, identificamos que el ejercicio de la ciudadanía plena y su correlato en la participación política viene aparejado de ciertas condiciones sociales previas a esta acción, como el acceso al bienestar, a la educación y la salud, a la igualdad, al empleo digno, rasgos en estrecha relación con la acción del Estado, que genera en el escenario político las condiciones ligadas a la capacidad y acceso de los actores a la representación simbólica, comunicativa, en el espacio público-político, a la acción política y al reclamo en defensa de derechos.

Si se visualiza la cuestión desde este prisma, es evidente que en el contexto de globalización ${ }^{1}$ actual, y del neoliberalismo que imperó con fuerza en el cono sur americano, donde el Estado se alejó de sus funciones otrora benefactoras, el ejercicio pleno de la ciudadanía se puso en cuestión, tanto desde la práctica como desde la teoría.

Los Estados latinoamericanos están hoy en una etapa de redefinición, luego de su prolongada ausencia en el neoliberalismo de la década de los 90. En este sentido, ha ido creciendo la interpelación a la cuestión de la ciudadanía y la urgente redefinición teórica que muchos investigadores están realizando a raíz de los fenómenos sociales, políticos, económicos, culturales y tecnológicos.

Antes de ocuparnos de las vertientes teóricas que abordan el concepto de ciudadanía y relacionarlo con los estudios de comunicación actuales, se debe destacar que estas consideraciones nos permitirán aproximarnos con mayor solidez a un proceso tan complejo como es la construcción de la identidad ciudadana de los pequeños productores agropecuarios de Corrientes, agrupados en organizaciones civiles.

A continuación, haremos un recorrido -inacabado, cabe aclarar- respecto de los desarrollos y consideraciones teóricas del concepto de ciudadanía, partiendo de la inaugurada por Thomas $\mathrm{H}$. Marshall a fines de la década del 40, pasando por las consideraciones de Guillermo O’Donnel, Jürgen Habermas, Hannah Arendt y Chantal Mouffe, y hasta las posturas latinoamericanas de la CEPAL, Manuel Garretón, Martín Hopenhayn y María Cristina Mata, autores que comparten su preocupación respecto de la relación entre política y ciudadanía unos, y entre ciudadanía y comunicación, otros.

Fue el sociólogo inglés Thomas H. Marshall (1949) quien inauguró el recorrido histórico de la ciudadanía y la problematización a partir del análisis de la reivindicación de derechos civiles, políticos y sociales y su relación con la clase social y la desigualdad a mediados del siglo pasado. En una conferencia en Cambridge titulada Ciudadanía y Clase Social, apunta y desarrolla esta temática, inaugurando la línea denominada "ciudadanía social". Marshall define a la ciudadanía como "un status que se otorga a

\footnotetext{
1 "La globalización puede verse como un proceso que genera nuevas 'vulnerabilidades' no incluidas dentro de la matriz teórico-institucional que guió las funciones sociales del Estado moderno y particularmente del Estado de Bienestar". (Filgueira, 1997: 129)
} 
los que son miembros de pleno derecho de una comunidad. Todos los que poseen ese status, son iguales en lo que se refiere a derechos y deberes que implica". (Marshall, 1997: 312)

Habría que puntualizar que Marshall aporta el concepto de ciudadanía como resultado de una lucha a partir de derechos civiles, políticos y sociales ganados a lo largo de la historia contemporánea. En su desarrollo histórico - que inicia en el siglo XVIII - asigna a la ciudadanía tres elementos: el civil, que se relaciona con la exigencia de igualdad ante los otros; el político, vinculado con la capacidad y derecho de formar parte del cuerpo político o ser elector de miembros de tal cuerpo; y el social, entendido por Marshall como el "derecho mínimo de bienestar económico y seguridad, al derecho de participar del patrimonio social y de vivir la vida de un ser civilizado, conforme a los estándares corrientes de la sociedad" (Marshall, 1997: 303).

A grandes rasgos, el autor considera que los primeros "logros" en la construcción de la ciudadanía fueron los civiles en el XVIII, luego los políticos en el XIX y los sociales, prácticamente solapados al anterior, en el XX.

Sin desprestigiar el importante aporte realizado por el autor, su definición tradicional está siendo puesta en cuestión por autores de distintas ramas y vertientes teóricas ya desde fines de la década de los 80. Las discusiones sobre esta definición parten de dos veredas; una de ellas tiene que ver con el escenario latinoamericano y su imposibilidad de ser equiparado con una sociedad capitalista y moderna como la de Inglaterra en la que Marshall se inspiraba para definir la ciudadanía social. Este contexto imposibilita que su idea de ciudadanía sea universalmente aplicable y extensiva a comunidades donde, tal como señalan algunos autores, la presencia del Estado y la modernización política es débil (O’Donnel, 2004) y donde el capitalismo ha ingresado de forma desigual.

Otra de las críticas a esta ciudadanía social está vinculada con el hecho de que en esa concepción se subraya el elemento social por sobre el político, lo que genera más desigualdad y, por consiguiente, exclusión, en el marco de un sistema que se sustenta a partir de la distribución desigual de riquezas y de poder como es el capitalismo. Así lo señala Oraisón (2010: 81-82):

desde esta noción (...) sólo quien goza de estos derechos estaría habilitado para la participación política. Esta perspectiva pone en cuestión que los pobres, sujetos de la acción de tales instituciones de beneficencia estatal, sean ciudadanos exactamente iguales a todos los demás. Los excluidos sociales, por el contrario, son considerados no-ciudadanos y esta condición parece ser irreversible hasta tanto no se asegure su derecho a ciertos niveles de vida que se consideran básicos para la relación de ciudadanía (Oraisón, 2010: 81-82) 
La línea crítica también cuestiona la concepción clásica de ciudadanía y la problematiza a partir del escenario de globalización, acentuando y señalando el carácter pasivo que subyace de la conceptualización de Marshall.

Desde esta posición, se asegura que la ciudadanía no está dada, sino que se construye a partir de la participación ciudadana y de la seguridad brindada por el Estado para que los espacios de participación existan y encaucen intereses colectivos. Por otro lado, también se considera que la disputa por el poder político y el espacio público y lo que este representa se llena de acciones de actores políticos que ya no encauzan sus reclamos solo con el Estado, sino que se enfrentan a actores diversos que afectan sus intereses de grupo, lo que los lleva a reunirse y movilizarse (Hopenhayn, 2001; Garretón, 2006).

Esta línea republicana de la ciudadanía la postulan intelectuales como Jürgen Habermas, quien afirma que a partir de las prácticas y acciones políticas materializadas en la participación con objetivos transformadores y con base en la racionalidad se construye la ciudadanía. Respecto del potencial de la participación, el autor dice que

la participación política dirigida por intereses emancipatorios se orienta a tratar de poner sobre la mesa temas cuya relevancia afecta a la sociedad global, definir problemas y hacer contribuciones, introducir cambios en los criterios de formación de la voluntad política y presionar sobre los parlamentos y los gobiernos a favor de determinadas políticas. Pero a la vez, trata de generar contra-espacios públicos y contra-instituciones, fijar nuevas identidades y modos expresivos, normativos $y$ comunicativos de acción social que transforman la cultura. (Habermas, 1998, pp. 450 y 451)

La propuesta habermasiana se sustenta en que a partir de un consenso racional apoyado en la acción comunicativa con ciertos aspectos morales, se generaría esta participación de todos los sujetos en el espacio público-político.

Chantal Mouffe adhiere a la importancia de la participación en el contexto político contemporáneo pero desde una posición de democracia radical ${ }^{2}$, a partir de la cual discute el modelo ideal de Habermas, por considerar que el filósofo alemán dejó de lado un elemento crucial para la lectura de lo político, esto es, el elemento antagónico:

El pensamiento político de inspiración liberal democrática revela su impotencia para captar la naturaleza de lo político. Pues de lo que aquí se trata es precisamente de lo político y de la posibilidad de erradicar el antagonismo. En la medida en que esté dominada por una perspectiva racionalista, individualista y universalista, la visión liberal es profundamente incapaz de aprehender el papel político y el papel

\footnotetext{
2 Además de la autora, en esta línea vinculada con la teoría radical se incluyen pensadores contemporáneos que tienen en común la crítica al pensamiento democrático liberal hegemónico, como es el caso de Ernesto Laclau, Slavoj Zizek y Alain Badiu, entre otros.
} 
constitutivo del Antagonismo (es decir, la imposibilidad de constituir una forma de objetividad social que no se funde en una exclusión originaria). (Mouffe, 1999:12)

Considera que el espacio político de la democracia liberal "no es un espacio neutro en el que se enfrentarían intereses en competencia [...]. Se trata de un espacio cuya formación es expresión de las relaciones de poder, y éstas pueden dar lugar a configuraciones interiores muy distintas" (Mouffe, 1999: 24). En esta línea de ideas, define la construcción ciudadana como

ejercicio de la democracia en las relaciones sociales, que son siempre individuales y específicas, lo que requiere una real participación en las prácticas sociales que tejen la trama tanto del Estado como de la sociedad civil. Por tanto, no se trata de desembarazarse de las determinaciones particulares, de negar las pertenencias ni las identidades para acceder $a$ un punto de vista donde reinara el individuo abstracto y universal. Hoy en día, el ciudadano democrático sólo es concebible en el contexto de un nuevo tipo de articulación entre lo universal y lo particular (Mouffe, 1999: 21)

En la línea de relaciones de poder que generan dinámicas de inclusión/exclusión y sobre la crítica respecto de la concepción clásica y universalista de la ciudadanía, también podemos encontrar el aporte respecto de la ciudadanía diferenciada de Young (1989):

en una sociedad donde algunos grupos son privilegiados mientras otros están oprimidos, insistir en que, como ciudadanos, las personas deben dejar atrás sus filiaciones y experiencias particulares para adoptar un punto de vista general, sólo sirve para reforzar los privilegios. Esto se debe a que la perspectiva y los intereses de los privilegiados tenderán a dominar este público unificado, marginando y silenciando a los demás grupos (Young, 1989, pág. 257) 3

También la CEPAL, centro de estudios en la región dependiente de la ONU y organización referente de América Latina y el Caribe, apuesta por la vertiente republicana:

Sin desmerecer la vigencia de este concepto de ciudadanía [titularidad de derechos dados al ciudadano por el Estado], es importante incorporar la tradición republicana, según la cual el ejercicio ciudadano se centra en el compromiso activo de las personas con el destino de la sociedad. Para construir sociedades más participativas y solidarias, no basta un Estado garante de derechos; es igualmente necesario contar con actores

\footnotetext{
${ }^{3}$ La traducción es nuestra. En el original: "In a society where some groups are privileged while others are oppressed, insisting that as citizens persons should leave behind their particular affiliations and experiences to adopt a general point of view, serves only to reinforce that privilege; for the perspectives and interest of the privilege will tend to dominate this unified, public, marginalizing or silencing those of other groups".
} 
sociales que se preocupen por los diversos aspectos del desarrollo y por la ampliación de espacios deliberativos (...). (CEPAL, 2010: 65)

El sociólogo chileno Manuel Garretón, por su parte, también pertenece a este debate teórico sobre la construcción de ciudadanía y cómo esta ejerce en las relaciones entre el Estado y la sociedad civil. El autor considera esta relación en el contexto de globalización y el debilitamiento del Estado-nación, lo que ha provocado dos consecuencias. La primera son las transformaciones en la ciudadanía latinoamericana, lo que lo lleva a considerar dos tipos de ciudadanía, las ciudadanías imaginadas o deseadas y las ciudadanías institucionales o clásicas.

Las primeras son las que reivindican algo que se siente como derecho y "que está en un campo de poder pero que no se tiene institucionalidad para ejercerse" (Garretón, 2006: 52). El autor apunta que esta reivindicación de derechos y responsabilidades no se dan solo frente al Estado o el poder político, sino que comienzan a darse en distintas esferas, como la medioambiental, la comunicacional, en relaciones de género, y generan nuevos campos de poder "que plantean problemas nuevos sobre como ejerce la ciudadanía" (Garretón, 2006: 52).

Las segundas, institucionales o clásicas, las considera debilitadas por la pérdida de poder y de representación de organizaciones en las que otrora se plasmaba, como los sindicatos.

Una segunda consecuencia del fenómeno de la globalización es la exclusión, ya que se prescinde de vastos sectores de la sociedad civil en términos de "marginación y distanciamiento progresivo, de manera que los excluidos no entran como sectores subordinados $u$ oprimidos en la sociedad que busca su emancipación, sino que simplemente no entran o sobran" (Garretón, 2006: 53).

Su análisis está enfocado en la necesidad de reconstruir la polis, la comunidad política, para recomponer las relaciones entre el Estado y la sociedad civil a través del debate sobre lo que "quieren ser"; en este sentido, Garretón concluye que "en esto consiste en estado profundo de la sociedad civil y la ciudadanía, ser los espacios y actores donde se debate el o los proyectos de sociedad" (Garretón, 2006: 58).

Entre los estudios que relacionan comunicación y ciudadanía, encontramos a Martín Hopenhayn, quien pone el acento en la importancia que tiene el acceso a la comunicación y su relación con la construcción y ejercicio ciudadano. Desde su postura, "el ejercicio efectivo de derechos [económicos, sociales y culturales] debe complementarse con nuevas formas de ciudadanía, vinculadas con el acceso al intercambio mediático y la mayor participación en la sociedad del conocimiento" (Hopenhayn, 2001: 117). Entendemos que las nuevas formas de ciudadanía van de la mano de nuevas formas de participación y nuevas formas de ocupar el espacio público.

Siguiendo también a este autor, consideramos que la construcción de ciudadanía no se da solo en un ámbito de participación política tradicional, sino que los sujetos 
comienzan a participar "en ámbitos de 'empoderamiento' (empowerment) que va definiendo según su capacidad de gestión y también según su evaluación instrumental de cuál es el más propicio para la demanda que quiere gestionar" (Hopenahyn, 2001: 119), y en este sentido, la idea republicana de la acción política reaparece más bien ampliada hacia "una gran variedad de prácticas de asociación o comunicación en la trama social que no necesariamente confluyen en lo público-estatal" (Hopenhayn, 2001: 119).

El autor enfoca su análisis hacia la construcción cultural de la ciudadanía democrática, por lo que presta especial atención a los impactos que sobre esta tienen la posmodernidad y la globalización. Ante este contexto de desigualdad y de exclusión de muchas voces, concluye que la ciudadanía democrática requiere "repensar hoy el contenido de este pacto o contrato, en el cual deben caber las voces de una amplia gama de actores sociales, y que debe tener capacidad real de prescribir formas de reciprocidad y reconocimiento horizontal" (Hopenhayn, 2001: 127). Desde este enfoque evaluaremos las prácticas y discursos de los representantes de las organizaciones campesinas de Corrientes, en el marco de una nueva concepción de la ciudadanía, premisa a partir de la cual partimos para comenzar esta indagación.

Es tal vez María Cristina Mata una de las investigadoras argentinas en comunicación que más se ha enfocado en nuestro tema en cuestión. En Mata (2005a), la autora hace una reivindicación acerca de las acciones ciudadanas de tradición republicana que se dieron en Argentina luego de la crisis de 2001. En referencia a las asambleas en plazas y calles, a los piquetes y a los movimientos que seguían la consigna "que se vayan todos", la autora dice que

Lenta y desigualmente, estas prácticas ciudadanas novedosas, realizan esa conjunción de discurso y acción que confiere poder. En ciertos casos, sea con el recurso a medios (...) con la producción de un espacio público urbano que altera la fisonomía de los ámbitos cotidianos de interacción, hay una ciudadanía que se constituye desde lugares diferenciados y que desde ellos busca no sólo su expresividad particular sino imaginar un futuro común y diferente. (Mata, 2005a: 72-73)

Mata, desde una postura de construcción de ciudadanía desde espacios alternativos, defiende la relación entre comunicación, ciudadanía y política, amenazada por las "exclusiones impuestas por los modelos sociales y económicos hegemónicos" y porque "la regulación técnica de lo representable como práctica ciudadana y política en el espacio público dificulta la aparición en él de la diferencia radical, única posibilidad de construir alternativas de poder". (Mata, 2005a: 72-73)

Hace menos de una década, la autora emprendió un análisis cuyo objeto de estudio es lo que denomina "ciudadanía comunicativa" (Mata, 2005b), a la que define como reconocimiento y ejercicio de derechos a la información y comunicación, cuya importancia está en el reconocerse como sujeto de demandas y propuestas. 
La autora define cuatro dimensiones de la ciudadanía comunicativa: la formal, que es representada por el conjunto de derechos consagrados en constituciones, declaraciones y pactos internacionales; la comunicativa, en tanto conocimiento que los individuos tienen de esos derechos por ser integrantes de una comunidad; la ciudadanía comunicativa ejercida, que comprende las prácticas sociales reivindicatorias de esos derechos; y la ciudadanía comunicativa ideal, que se plantea como meta casi inalcanzable (Mata, 2005b).

El análisis de Mata se sustenta en una lectura acerca de la desigualdad en el acceso a la palabra pública, y en la idea de que el poder comunicativo se sostiene a partir de una hegemonía que excluye a los individuos que carecen de posibilidades de expresión.

Compartimos con Mata esta lectura acerca del intercambio comunicativo en el espacio público, ya que consideramos que los grupos vulnerables social y económicamente también contienen, como una dimensión tan importante como las mencionadas, una vulnerabilidad semiótica o comunicacional (López, 2009; Quintana, 2011).

El abordaje específico sobre el fenómeno de la vulnerabilidad semiótica del pequeño y mediano productor del NEA a través del análisis del discurso puede encontrarse en quien dirigió esta investigación, Marta Susana López (2009, 2009b, 2010 y 2012), quien cuenta con diversos trabajos publicados, y en las integrantes del equipo de investigación del que López es asimismo responsable, Emilas Lebus (2012) y Manuelita Núñez López (2012).

Los procesos de exclusión propios del sistema imperante, sin embargo, hacen emerger movimientos sociales reivindicadores de distintas concepciones de lo ciudadano y colectivos de distintos ámbitos y con diversos reclamos que buscan diferenciar su identidad a través de su manifestación en el espacio público ${ }^{4}$, y es en esas múltiples esferas de lo público (Bonilla, 2006) donde buscamos las prácticas y discursos de los campesinos, porque entendemos que es allí donde se expresan con fuerza las relaciones de dominación y resistencia.

\section{¿Desde dónde vemos la construcción de identidad?}

La filósofa alemana Hannah Arendt postula en "La Condición Humana" (Arendt, 1993) la importancia de la acción y el discurso en el ámbito político. Su aporte nos permite definir la categoría de "identidad ciudadana", al entender que: "Mediante la acción y el discurso, los hombres muestran quiénes son, revelan activamente su única y personal identidad y hacen su aparición en el mundo humano" (Arendt, 1993: 203).

\footnotetext{
${ }^{4}$ Este espacio construido semióticamente por los discursos sociales, pero también por la presencia indicial de los cuerpos en las manifestaciones públicas, es un espacio público y político (López, 2009b).
} 
La importancia de la acción y el discurso en la conformación de la identidad dentro del ámbito público y, a la vez, político, se hace evidente:

Pluralidad no es idéntica a simple alteridad (otherness.); pluralidad tiene que ver con distinción, tiene que ver con lo que se muestra a través de la acción y del discurso. (...) La distinción es propia de la acción humana. En la medida que pluralidad significa distinción, es posible la revelación —en el medio público- de la individualidad de cada uno, de la identidad (whoness). (Arendt, 1997: 20)

La base de Arendt también está dada por la idea de la diferenciación, es decir, "yo soy lo que otro no es". Esta diferenciación también es destacada por Hopenahyn a la hora de hablar de ciudadanía: "la diferenciación de los sujetos implica que la ciudadanía se cruza cada vez más con el tema de la afirmación de la diferencia y la promoción de la diversidad" (p. 119).

Teun Van Dijk, desde el análisis crítico del discurso, entiende que las prácticas discursivas están regidas por ciertas representaciones sociocognitivas que "indican" cómo deben expresarse los actores que manifiestan su discurso. En nuestro abordaje, siguiendo al autor, hacemos foco en el modo en que los miembros de un grupo se ven y representan a sí mismos a través del discurso y cómo hacen lo propio con los Otros. En este aspecto, es conveniente poner atención en la relación de polaridad que se establece en el texto representado por el esquema Nosotros-Ellos, o cuadro ideológico (Van Dijk, 1999).

La construcción de ciertos emisores y ciertos receptores, y la implementación de un Nosotros y de un Ellos para mantener los dos polos que se encuentran en conflicto, es un punto fundamental que hay que tener en cuenta a la hora de realizar el análisis de la construcción identitaria. Esta polarización sirve —siguiendo a Van Dijk- para identificar ciertas actitudes en los discursos de los actores sociales, y de esa manera inferir la ideología subyacente, ya que "las actitudes son conjuntos de creencias evaluativas socialmente compartidas" (Van Dijk, 1999: 93).

Esta polarización entre Nosotros y Ellos se identifica, cuando los grupos construyen una imagen ideológica de sí mismos, siempre positiva, y de los otros, siempre negativa. Estas polarizaciones implican acuerdos sociales en cuanto a lo que se considera bueno y malo en cada situación determinada: "Esos arreglos sociales son especificaciones de valores más generales" (Van Dijk, 1999: 95).

Interesa esta visión de Van Dijk porque considera que a través de los esquemas de grupo que "indican" sus comportamientos sociales, estructurado según la ideología subyacente, las prácticas "permitidas" tienen una relación directa con la identidad del grupo: "Si las ideologías controlan el modo en que la gente, como miembros de grupo, interpretan y actúan en su mundo social, también funcionan como la base de su identidad social". (Van Dijk, 1999: 98) 
Estas posturas mencionadas, los aportes del análisis del discurso político y la premisa fundante del análisis de la teoría de los discursos sociales, que establece que toda producción de sentido es necesariamente social y todo fenómeno social es un proceso de producción de sentido (Marafioti, 2004: 95), son las nociones que nos guían en el proceso de indagación sobre la construcción de la categoría de identidad ciudadana de los pequeños productores agropecuarios de Corrientes.

\section{Contexto histórico, político y económico de los discursos}

El proceso de expansión de la frontera agrícola fue de la mano de un proceso de expulsión de familias rurales, a partir de políticas implementadas del gobierno de Menem y de De la Rúa (1989/1995-1995/1999, 1999/2001, respectivamente), como la destrucción de las Juntas Reguladoras (de Granos y de Carnes), los recortes de presupuesto en organismos claves en el desarrollo del sector (INTA, SENASA, INASE), en particular los vinculados con la generación y transferencia de tecnología (Grünfeld y Morcelle, 2003) .

El Censo Agropecuario de 2002 lanzó alarmantes cifras en las que puede leerse la fenomenal política de concentración de tierras, por un lado, y de expulsión campesina, por otro. En el marco de este escenario de conflicto hacia adentro y afuera del complejo mundo rural, los pequeños productores agropecuarios libran la batalla por su supervivencia. Las políticas neoliberales de los noventa repercutieron en la expulsión de los campesinos del campo y la concentración de la tierra en pocas manos, lo que pone a estos actores en un duro espacio de combate por su reconocimiento y supervivencia.

Más allá de que el Informe de la CEPAL del Panorama Social de América Latina 2011 indica que Argentina está dentro de los cinco países que registraron disminuciones significativas en sus tasas de pobreza entre 2009 y 2010 —junto a Perú, Ecuador, Uruguay y Colombia-, en la región más desigual del mundo, Latinoamérica y el Caribe, existen microrregiones donde se evidencian con mayor intensidad los resultados de la ausencia de políticas públicas y el advenimiento del individualismo propio de la globalización y el modelo neoliberal.

En este sentido — según datos publicados por el INDEC en su Encuesta Permanente de Hogares Continua-, el nordeste argentino (NEA) es la región con el índice más alto de personas y hogares bajo la línea de la pobreza a nivel país, y asimismo, lidera los índices de personas y hogares bajo la línea de la indigencia. En este territorio signado por la desigualdad y la pobreza, se instalan también brechas políticas, que repercuten en la posibilidad de los sujetos de generar y ocupar espacios de participación y transformación.

Los pequeños productores rurales de Corrientes — provincia integrante de la región NEA - se instalan en un escenario rural que no está exento del impacto de las políticas de carácter global. Considerados "vulnerables" por el abandono e invisibilidad que sufre el sector, entendemos que las políticas neoliberales repercuten - de una u otra 
manera - en su modo de subsistencia, y ponen en juego la construcción de su identidad particular y de su ciudadanía.

A nivel productivo y territorial, se caracterizan por ser minifundistas que dependen de la mano de obra familiar y que comercializan la producción ampliada, a lo sumo, en el mercado interno. En el plano político, las organizaciones civiles nuclean a productores agropecuarios, son un espacio de debate y reflexión sobre problemáticas comunes, como tenencia y titularidad de la tierra, la vida campesina y la generación de proyectos para presentar al Estado en busca de subsidios. También se conforman en espacios donde se concretan ideas, pedidos y reclamos para ser presentados en las reuniones de las mesas provinciales de tierra o el foro de agricultura familiar. Por su parte, en el caso de la Asociación Provincial de Pequeños Productores de Corrientes (APPPC), gracias al valor del asociativismo y la solidaridad de los productores, se han construido casas para los socios más vulnerables, y han ayudado a otros tantos en la compra de alambrados, semillas e insumos que hasta una pequeña parcela de tierra requiere para su cultivo.

Entendemos que los pequeños productores agrupados en estas asociaciones civiles tienen un tímido carácter de subalternidad; ellos se diferencian del "nuevo tipo de sujeto agrario" (López, 2010: 5) que mantiene la hegemonía e instala puntos de debate con los "otros" actores fuertes de lo público: el Estado, los grandes productores agropecuarios, los empresarios de pooles de siembra, que por su poder tienen acceso a la construcción del espacio público, a manipular las agendas de los medios y a ejercer influencia en la opinión pública.

En 2006, en tanto espacio de participación política promovida desde el Estado, surgió el Foro de la Agricultura Familiar (FoNAF), que en la actualidad, según algunos de sus integrantes que han sido informantes en este trabajo, es un espacio donde la discusión política ya no se pone de relieve. Por otro lado, para algunos investigadores:

la conformación del FoNAF como expresión de la agricultura familiar genera una serie de tensiones. Las mismas giran en torno a la amplitud del concepto de agricultura familiar, la función del Estado en la conformación de una "organización", como también al rol de entidades gremiales del sector agropecuario que si bien tienen puntos de contacto con la agricultura familiar también tiene sus divergencias (García Guerreiro et. ál., 2009: 10).

La reflexión que proponemos se da a partir de las voces de los pequeños productores rurales correntinos, haciendo foco hacia adentro y hacia afuera de las acciones simbólicas de las entidades civiles que nuclean a los campesinos denominados "pequeños", a partir de sus discursos mediatizados plasmados en un periódico de comunicación alternativa como Acción, que les brinda un espacio de participación de lo público, que por más de que sea restringido, llega a aquellos que 
son parte de la realidad que desde estos discursos mediatizados se construye ${ }^{5}$; a su vez, también la reflexión se da a partir de entrevistas semiestructuradas con algunos referentes políticos de estas asociaciones.

\section{Articulaciones: discurso político de pequeños productores agropecuarios}

Como podría inferirse de las tesis de Arendt (1993; 1997), el ciudadano que no se manifiesta en la arena pública de una u otra manera tiende a no existir. Es decir, aquel que no se enuncia como un "yo", como vocero de su identidad en tanto interlocutor reconocido y válido, deja de ser parte de la pluralidad, es un excluido de la esfera pública y política.

Tal como hemos desarrollado en el apartado anterior, entendemos que la participación contribuye a la inclusión social; sin embargo, a veces no están dadas las condiciones óptimas para que todos los grupos que conforman una sociedad consoliden dicha participación, teniendo en cuenta que la disputa por el poder margina a aquellos más débiles económica y comunicacionalmente (López, 2009).

Uno de los tantos grupos "al borde de la exclusión" son, justamente, los pequeños campesinos, quienes trabajan la tierra por cuestiones de subsistencia y costumbre, alejados de los intereses capitalistas de otros con quienes comparten el primer eslabón de la cadena de producción (grandes productores, empresarios de pooles de siembra). Son productores minifundistas, que sobreviven gracias a la mano de obra familiar, y que no responden a una cadena productivista de tipo plenamente capitalista (Chayanov, 1974).

\section{El discurso político en "Acción"}

Citaremos a continuación extractos de crónicas y noticias referidas a acciones de las organizaciones civiles de pequeños campesinos, entendidas como actividades cargadas de significación política por identificarse con la toma o ejercicio del poder, o de la resistencia. A pesar de que la gama de acciones políticas son amplias, el foco está puesto en crónicas y noticias que relacionen sus discursos con la participación de los campesinos para generar un cambio en las condiciones dadas, con las manifestaciones en defensa de ideas y con el reclamo y defensa de sus derechos (a la tierra y al agua, fundamentalmente), entendidas como características de un tipo de resistencia simbólica y física por un lado, y del establecimiento y ejercicio de una identidad ciudadana, por otro.

\footnotetext{
${ }^{5}$ En otro estudio concluimos que en un momento específico de la historia argentina, como fue el enfrentamiento entre el "campo" y el Gobierno, la prensa tradicional que estudiamos (los diarios El Litoral y El Libertador de Corrientes) no representaban en su mundo posible mediático a los pequeños y medianos productores agropecuarios de la provincia, desconociendo su particular identidad, y homogeneizando sus reclamos junto con los de las cúpulas agropecuarias desde las que se destacaba un discurso hegemónico de carácter liberal agroexportador (Quintana, 2010).
} 
Una premisa fundamental de esta investigación es que la disputa física y simbólica de estos grupos considerados vulnerables se juega en dos planos interligados; el político (a través de marchas, cortes de ruta, reuniones de reflexión y participaciones en foros en pos de la unión campesina) y el económico, en tanto uno de los aspectos desde el cual estos sujetos manifiestan su resistencia imponiendo tímida pero decididamente un tipo de comercialización "diferente" del hegemónico (como el caso de las Ferias Francas) en el marco de una lógica de mercado que al pequeño productor agropecuario le resulta extraña y hasta nociva para su supervivencia en el campo.

Para la aproximación a los discursos mediatizados de organizaciones civiles de pequeños productores rurales de Corrientes, tomamos como fuente de datos el mencionado periódico Acción. Esta publicación mensual ${ }^{6}$ del Instituto de Cultura Popular (InCuPo) comenzó a editarse en el año 1971. Desde entonces tiene el mismo objetivo:

rescatar y difundir saberes y experiencias de comunidades rurales campesinas $y$ aborígenes del norte argentino, es un espacio de expresión para estos hombres y mujeres que padecen situaciones de pobreza y que en muchas ocasiones son excluidos o estigmatizados por los grandes medios de comunicación ${ }^{7}$.

El archivo de Acción recopilado para esta investigación está conformado por 68 ejemplares que van desde febrero de 2006 a octubre de 2012. A partir de las primeras lecturas, identificamos una fuerte visibilidad de distintas organizaciones campesinas como protagonistas de sus páginas.

Partimos de la premisa de que este medio funcionaría como una herramienta de resistencia, ya que llega a sectores rurales del norte argentino donde en ocasiones la prensa tradicional no llega, y lleva un mensaje de "unión" y "lucha campesina". Mencionamos anteriormente que consideramos que por más que el espacio público en que se introduce Acción es restringido en comparación con los periódicos tradicionales y su papel en la construcción de la opinión pública, su valor radica justamente en su rol desde la perspectiva de la comunicación alternativa, proporcionando al público al que llega un (auto) reconocimiento en los discursos que se plasman en sus páginas.

Luego de esta sucinta justificación del corpus de la primera articulación, cabe destacar en este punto que en las citas que se presentan a continuación el foco de la indagación está puesto —en una primera instancia- en el discurso político mediatizado de los enunciadores en este medio de comunicación alternativa, para luego compararlo con lo que los referentes nos han dicho en las entrevistas.

En una crónica de abril de 2008, cuando el conflicto entre el "campo" y el gobierno de Cristina Fernández de Kirchner estaba comenzando, el periódico publica:

\footnotetext{
${ }^{6}$ Desde abril de 2012 es bimestral.

${ }^{7}$ Disponible en página web de la publicación: http://incupo.org.ar/index.php?option=com content\&task=blogsection\&id=4\&Itemid=98
} 


\section{ESTAS VOCES TAMBIÉN SON EL CAMPO}

Santiago Soto, secretario de la APPPC aportó su sentimiento, reclamos y propuestas: 'el pequeño productor presta un gran servicio a las comunidades principalmente chicas, porque produce lo que se come todos los días, alimentos frescos, sanos. Ya no está usando agroquímicos, todos sabemos lo mal que hacen a la vida del ser humano. Nosotros decimos que el pequeño productor tiene que seguir viviendo del campo...pero con las comodidades que hay en la ciudad...no porque se le ocurra, sino porque está prestando un servicio muy necesario a la comunidad, en un tema importante como es la alimentación sana y saludable". (Acción, abril de 2008: 7)

En el extracto, notamos cómo el medio destaca la postura del enunciador, quien recalca la función social que cumple el pequeño productor en la comunidad. El representante de agricultores familiares de Corrientes es el portavoz del mensaje de los campesinos, el cual es "que se deje al pequeño productor seguir viviendo en el campo". Instala un "nosotros" en su discurso que expone la identidad del campesino; esta es la del productor que no usa agroquímicos y produce alimentos frescos y sanos, a diferencia de los "otros" —o de "ellos"—, que son los grandes productores agropecuarios que por oposición, se entiende, sí los utilizan en sus cultivos poniendo en peligro la salud de los consumidores y el medio ambiente. A partir de esta oposición se comprende la importancia de la argumentación de que los pequeños campesinos producen para que la comunidad viva de manera "sana y saludable". Podría definirse a este nosotros como un nosotros colectivo campesino.

El discurso intermediario es entendido como el que "se construye a sí mismo mediante la palabra ajena" (Chirico, 1987: 60). A partir del foco en lo que se considera el discurso intermediario del periódico Acción, nos aproximaremos a su rol en la visibilidad de la resistencia campesina, y en el proceso de la imagen que brinda de la identidad ciudadana de estos sujetos.

El discurso intermediario aparece en el extracto a partir del uso de la cita directa del discurso del representante de la Asociación Provincial de Pequeños Productores de Corrientes. El medio privilegia mostrar el discurso directo del campesino entrecomillado, brindando una sensación de supuesta objetividad en la construcción de la crónica.

El reclamo deviene en respuesta de una política de expulsión existente, en la que los pequeños productores agropecuarios terminan abandonando sus tierras por la presión de los "grandes productores", en su afán por obtener más tierras para monopolizar el mercado a partir de cultivos con buenos rendimientos en la balanza de comercio internacional. Este éxodo particularmente en Corrientes también está muchas veces relacionado con la foresto-industria que arrasa los montes del norte argentino, y que aun la sancionada Ley de Bosques Nativos no ha podido paliar.

En otra crónica de Acción, aparece lo siguiente: 


\section{SABOR Y AROMA A CAMPO CORRENTINO}

Los campesinos de Corrientes realizan producciones muy diversas y esto es una gran ventaja. Teniendo en cuenta que en otras provincias predomina el 'monocultivo'. Por suerte, en nuestra provincia, los cultivos industriales como el tabaco, el algodón y la yerba mate, que comenzaron a sembrarse en el siglo pasado no eliminaron la producción para el autoconsumo. En pequeña escala los campesinos siguieron produciendo maíz, batata, mandioca, maní, porotos y muchas otras cosas más. (Acción, agosto 2008: 5-6)

En la misma nota, más adelante agrega: "Hoy son muchos los intereses que atentan contra la producción campesina. Las grandes empresas forestales y arroceras están arrinconando a las familias en las tierras ya muy subdivididas de sus antepasados". (Acción, agosto de 2008: 5-6)

El discurso intermediario funciona aquí construyendo también un "nosotros" a partir de la enunciación del medio. Esta figura colectiva utilizada por el enunciador -a diferencia de la del discurso del representante campesino de la primera cita- se vincula con un grupo que podría incluir a los campesinos, pero que no se restringe solo a ellos, sino que construye su estrategia discursiva a partir de un nosotros ampliado al territorio provincial, que reivindica la batalla campesina por su subsistencia.

Para generar la adhesión a esa reivindicación, toma como estrategia el territorio compartido con el interlocutor al hablar de "nuestra provincia". Desde este punto en común, remarca la diversidad de las producciones agrícolas, su importancia en el autoconsumo de las familias agropecuarias y de qué modo vienen resistiendo ante las amenazas de las producciones industriales y el avance del adversario: las "empresas forestales y arroceras".

A partir de este discurso intermediario, entendemos que el medio va configurando el mundo posible mediático, y que al tener una distribución en todo el norte argentino, se instala también como una herramienta que apoya a la resistencia, haciendo emerger y visibilizando —al menos en espacios no tradicionales o alternativos - la problemática campesina.

Otra crónica de Acción, en este caso del mes de noviembre de 2006, se puede leer:

\section{SOBERANÍA ALIMENTARIA Y POLÍTICA}

Gerardo Baez (...) vive en colonia El Desmochado, Departamento de Bella Vista, provincia de Corrientes. Es un pequeño productor y pertenece al Movimiento Campesino de Corrientes. Él nos dice así:

Nosotros siempre trabajamos con producción natural. Para eso, en primer lugar hay que darle a la tierra el valor que se le debe dar. Así, nosotros rotamos la chacra, ponemos porotos, pasturas. Trabajamos con los rastrojos. Los dejamos, sin quemarlos. Dejamos que la tierra verdaderamente consuma lo que es de ella. De esa manera vamos mejorando el suelo. De ese modo, realmente se puede mejorar el suelo y mejorar la producción. Y no 
hay que ponerle cosas que degraden la tierra, como los abonos químicos y los demás agroquímicos. Hoy, cuidar la tierra y darle su valor es algo de suma necesidad. (Acción, noviembre de 2006)

En esta cita se pueden mencionar varios niveles de análisis. En principio, puede decirse que el integrante del Movimiento Campesino de Corrientes diferencia la producción del pequeño campesino con la de los grandes, en su no utilización de agroquímicos para proteger la producción, e instala a la forma de producir campesina como un modelo productivo rentable y sustentable, que se inspira en una filosofía de fraternidad y respeto con la naturaleza. Establece claramente lo que consideramos un nosotros campesino.

En el apartado citado, se puede interpretar la existencia de un oponente implícito, el cual sería aquel productor rural que utiliza agroquímicos, y que por esta práctica degrada la tierra, negándole su verdadero valor.

El medio señala en la misma crónica, más adelante: "Los campesinos y campesinas no sólo cosechan maíz, mandioca, batata, zanahoria, frutas, hortalizas y crían animales. También producen soberanía alimentaria. Y además, producen cultura, identidad, solidaridades"8.

En esta cita, notamos el discurso intermediario de Acción cuando utiliza una estrategia argumentativa que hace que sus interlocutores (campesinos y campesinas) relacionen directamente su modo de vida y subsistencia en tanto productores agropecuarios con su capacidad de también "producir" cultura, identidad y solidaridad. El discurso intermediario es crucial en este punto, ya que a partir de una metáfora logra que el lector pueda "comprender lo desconocido, apoyándose en lo conocido" (Chamuceiro, 2004: 111).

Otra crónica de febrero de 2009 de Acción marca la relevancia de la participación:

\section{YO TE RECLAMO, TIERRA}

A partir de un panel de experiencias y aportes técnicos-jurídicos, los técnicos y campesinos conocieron las herramientas necesarias para defender el derecho a la tierra.

La participación campesina y las experiencias de lucha por su tierra fueron el insumo fundamental para la reflexión. (Acción, febrero 2009: 18-19)

Acción destaca en este extracto la importancia de la lucha por la tierra de los campesinos, lucha con la que está de acuerdo. Como se mencionó, debido a la expulsión que se viene dando por la disputa de otros actores fuertes que transformaron al agro en un negocio, la problemática de la tierra es lo que moviliza políticamente a las organizaciones campesinas, generando espacios de participación y

\footnotetext{
${ }^{8}$ Las negritas corresponden a la publicación.
} 
reunión como Mesas Campesinas, Movimientos y Organizaciones. Estos espacios son los que Acción hace emerger y visibilizar a través del mundo posible mediático que crea con la interacción de sus discursos.

En coincidencia con Chirico (1987), entendemos que el discurso intermediario de Acción tiene un importante papel en la construcción de identidades sociales vinculadas con el sector del campesinado más pobre y vulnerable de la Argentina, porque es integrante de una cadena discursiva de comunicación en la que las asociaciones que nuclean a campesinos establecen ciertos valores a partir de sus discursos políticos. Vemos también que el medio funciona como una tímida voz en el escenario público, y que a pesar de que no se entabla en la opinión pública general, llega a su público objetivo, los campesinos del norte argentino.

Entendemos que el rol de Acción en la disputa simbólica por la construcción de realidades a través del discurso mediático es el de brindar a los campesinos un espacio en el que la participación en sus comunidades invita a los otros a movilizarse y también comenzar a participar en reuniones y convocatorias que busquen la transformación de las condiciones reales de existencia.

Acción se instala como un espacio mediático legítimo en el que las organizaciones campesinas pueden acceder a la palabra y a la comunicación pública, crucial para la construcción ciudadana (Hopenhayn, 2006).

Este periódico sirve para combatir desde las acciones políticas a las representaciones hegemónicas del complejo mundo rural, por un lado, y para que a través del empoderamiento se perciba el proceso de construcción de identidad ciudadana estableciendo las características de un "nosotros" que genera identidad y promueve acción a partir de los rasgos de la diferencia (Arendt, 1997).

\section{Participación, según los protagonistas}

Los extractos que citaremos a continuación pretenden tener una aproximación no mediatizada de su modo de concebir la participación, y de cómo establecen su identidad a partir de sus discursos. Entrevistamos a representantes de dos de las asociaciones civiles en las que nos enfocamos, la Asociación Provincial de Pequeños Productores de Corrientes (APPPC) y la Asociación Provincial de Ferias Francas. Cabe destacar que el estudio, del cual en este artículo proponemos una parte, aún está en desarrollo y quedan aún más entrevistas para procesar y analizar.

La APPPC se conformó oficialmente en 1991; dos años después, obtuvo su personería jurídica. En la actualidad, cuenta con unos 1200 asociados en diferentes departamentos del interior provincial. Es una asociación sin fines de lucro que nuclea a minifundistas, y como ellos mismos dicen "vienen luchando para no desaparecer". A través del extracto de una entrevista a Santiago Soto, antiguo dirigente de la APPPC y actual prosecretario, podemos inferir cuáles son desde la organización los beneficios de organizarse y participar. El informante dijo: 
Lo principal es que la gente se está dando cuenta que agrupándose tiene más chances de salir adelante. Muchos lograron titularizar sus tierras, consiguieron apoyos económicos del Estado, se construyeron viviendas rurales. (...). Con aciertos y errores, podemos decir con tranquilidad que son veinte años de trabajo comunitario y solidario, donde ningún dirigente percibe sueldo.

Nuestra esperanza es que la gente se siga sumando a la organización, construyendo un camino para que los más jóvenes puedan continuar esta lucha por las familias campesinas. (Marzo, 2011)

El dirigente destaca la importancia de la participación como una herramienta para sortear la difícil situación que están viviendo en el campo; al mismo tiempo destaca la identidad de la asociación a partir de la definición de su trabajo comunitario y solidario e instala el trabajo de la organización en un espacio de conflicto, al cual define como parte de la lucha de las familias campesinas. La inferencia respecto de los problemas de los campesinos que representa está vinculada con la titularidad de la tierra y las dificultades para conseguir financiación y una vivienda, por lo que la lucha se establece contra aquellos que los han llevado a esa situación problemática.

En la cita que se presenta a continuación, se hace evidente de qué modo el dirigente diferencia a la APPPC como espacio de participación y organización, de otros generados desde el Estado, como el Foro de Agricultura Familiar y el rol de la Subsecretaría de Agricultura Familiar en Corrientes para la generación de políticas públicas para el sector. Al respecto, Soto dijo:

Lo que no existe es el espacio de debate formativo. Entonces los que participan, son participaciones muy pasivas, porque se les fue formando que la participación es solamente venir a ver si avanzó o no el proyectito que se presentó en su zona. Cada uno viene a defender lo suyo. El clásico el árbol tapa el monte. (Abril, 2012)

Se puede comprender que el dirigente deja entrever que han sido convencidos por "los otros" de que participar es igual a financiación de proyectos puntuales, es la continuación de la subordinación a cambio de dinero estatal. Sin embargo, el dirigente pone sobre el tapete esa cuestión prevaleciendo el debate como condición verdadera de participación y estableciendo así los valores positivos del grupo al que representa y los negativos de aquellos con los que se enfrenta. Su discurso establece un cuadro ideológico (Van Dijk, 1999).

Por su parte, otra dirigente de la APPPC, la actual presidenta de la asociación, Tomasa "Pani" Vallejos, dijo:

Son muchos los problemas por resolver, las dificultades con el tema tierra, las cuestiones productivas, el fortalecimiento de la organización en cada departamento. No queda otra que salir a la calle a defender nuestros derechos. Así nos formamos, caminando, andando en la lucha. Sobre todo a las mujeres les pedimos que sigan 
participando unificando nuestro esfuerzo para mejorar la vida de la familia campesina. (Septiembre, 2011)

La dirigente establece claramente la identidad del grupo que representa, y resalta la importancia de la defensa de sus derechos. El estado de lucha o batalla es destacado también por la presidenta de la APPPC, a la vez que se evidencia la actitud de resistencia que pregona esta asociación. Asimismo, notamos cómo la dirigente se ocupa en diferenciar al grupo al que pertenece, el campesinado, como un sector que históricamente tuvo que ocupar espacios a partir de acciones políticas como manifestaciones y protestas. Sin embargo, notamos que la participación en el discurso de esta dirigente campesina está más vinculada con la lucha por derechos que con el debate y consenso.

Un comentario especial en el análisis puede hacerse respecto de cómo relaciona a la mujer con el mejoramiento de la vida de la familia campesina. La dirigente apela a las mujeres campesinas con la premisa de que son ellas las que tienen injerencia en lo doméstico y a la vez, en lo político, a través de sus acciones de participación. Podría decirse que lejos de ser una visión tradicionalista del rol de la mujer en el campo, esta frase permite identificar la importancia que se le brinda desde esta asociación a la mujer.

Las ferias francas surgen en Corrientes a partir de 1998 en la búsqueda de alternativas a la crisis de los cultivos regionales, como el tabaco, el algodón y la yerba mate, valorizando los productos que anteriormente se destinaban al autoconsumo. Esta crisis, agravada por la crisis política, económica, social e institucional en 2001 le dieron mayor impulso a estas formas alternativas de comercialización, y en el 2. ${ }^{\circ}$ Encuentro Provincial de Ferias Francas se conformó la Comisión Provincia, que luego constituyó la Asociación Provincial de Ferias Francas (APFF). Esta asociación agrupa a más de doscientos feriantes que participan de algunas de las veintidós ferias ubicadas en diferentes localidades de la provincia. En julio de 2009 obtuvieron su personería jurídica con el Nro. 4152/07.

Domingo Escalante, presidente de la Asociación Provincial de Ferias Francas, comentó respecto de la participación de la asociación en distintos ámbitos:

Estamos participando en todos los lugares donde vemos que es necesaria nuestra presencia, porque el problema de los productores son muchos. (...). Estamos participando en la Mesa Provincial de Tierra, porque nuestros productores tienen muchos problemas, y no sólo los nuestros, sino de toda la provincia. Estuve en el Encuentro Nacional de Semillas que se hizo en Catamarca, y las quejas, digamos, de todos los productores siempre es la misma, los están desalojando, y estamos participando en todos los lugares donde podemos ser útil, para ver qué podemos aportar para encontrar alguna vez una solución. (Julio, 2012) 
A diferencia de lo que se puede inferir de las citas de los líderes de la APPPC, este dirigente de la APFF establece el espacio de su organización como partícipe de otras entidades políticas, apuntalándose como una organización de apoyo para frenar los desalojos de los campesinos de sus tierras. Es decir, se muestra menos radical en su discurso frente al Estado.

Otro integrante de la Asociación Provincial de Ferias Francas de Corrientes dijo:

"La mayoría de los productores no tienen regularizada las tierras, entonces vienen las grandes empresas, y políticamente y económicamente, van ocupando las tierras. (...) Nosotros como Asociación buscamos que se mantengan las tierras, y que el productor, la familia y los chicos queden en el campo. Que valoricen la tierra más allá de lo que vale monetariamente...". (Julio, 2012)

La referencia a la labor educativa de la organización es central en este extracto, ya que es parte de una acción cargada de significación política, que contribuye a que el campesino comprenda cabalmente la importancia de mantenerse arraigado en la tierra que sabe cultivar y producir, y que no se deje engañar por los "otros", las grandes empresas que les quitan sus tierras, aprovechándose de su condición de vulnerabilidad social.

La participación está vinculada con la lucha campesina y con la importancia de la organización para llevar adelante la defensa de los derechos de las familias que viven en y del campo. La claridad en lo que la participación política significa es crucial para gestionar estratégicamente esta participación desde las organizaciones campesinas. Estas prácticas de asociación, y en el caso del periódico Acción, de comunicación, confluyen para articular la resistencia.

\section{Reflexiones finales}

La relación entre comunicación, política y ciudadanía se nos aparece en un contexto revolucionado por transformaciones en el ámbito cultural y político, signado por la globalización en el ámbito económico y administrativo, por el neoliberalismo en saliente y la sociedad de la información y comunicación en la que estamos inmersos. A pesar de que la comunicación ha sido crucial para el ejercicio de la política y de lo político desde la Antigüedad, en las últimas décadas tiene un papel decisivo para el sostenimiento de hegemonías, de consensos e, incluso, para contrarrestarlos.

Tal como mencionamos al principio, la articulación acción-discurso-identidad desde el marco teórico que nos permite dar luz sobre los procesos de construcción de sentido en que nos enfocamos está compuesta por autores que nos brindan ciertas herramientas teóricas con las cuales construimos la categoría de identidad ciudadana. El recorte de este marco está relacionado con los objetivos de investigación y con las intuiciones de quien indaga. 
Respecto del discurso intermediario identificado en Acción, es dable mencionar como reflexión final el importante papel del periódico en la construcción de identidades sociales vinculadas con el sector del campesinado más pobre y vulnerable de la Argentina. Lo consideramos una herramienta de comunicación que permite que estos actores silenciados en otros espacios sean interlocutores válidos dentro de un espacio público que, aunque restringido, aún se constituye como una esfera de lo público donde identificarse y establecer modelos y valores.

Por su parte, en la profundización del análisis de este periódico, también se hizo evidente de qué modo el recurso del territorio, en tanto elemento compartido, constituye una dimensión más de identidad común de estos campesinos. Este rasgo también emerge en las entrevistas a los dirigentes, quienes hacen hincapié en las problemáticas con la tierra y en el valor de la participación para la defensa de un territorio que por herencia y costumbre les pertenece.

Estos actores, los campesinos, toman la palabra en espacios alternativos, esferas de lo público, para encauzar sus reclamos e intereses estableciendo su carácter diferencial frente a quienes consideran los "otros", y en este tren de acción constituyen su identidad y ciudadanía.

Entendemos que la participación de estos grupos está en proceso de apuntalarse, a partir de lo cual sus voces se harían más fuertes en el entramado de discursos que construyen la realidad; están encaminados hacia el empoderamiento, y en ese proceso, también hacia la construcción de una identidad ciudadana que sea percibida en el espacio público-político, lugar donde las semiosis convergen para construir sentidos hegemónicos.

\section{BIBLIOGRAFÍA}

Arendt, H. (1993). La condición Humana. Paidós: Barcelona.

----------(1997) ¿Qué es Política? Paidós: Barcelona.

Bonilla, Jorge Iván (2006). "Cuando el discurso público no lo explica todo. Una mirada a la comunicación política en contextos de miedo, hostilidad". En: Pereira, José M. y M. Villadiego Prins, Entre miedos y goces: comunicación, vida pública y ciudadanías(pp.164-187). Bogotá: Pontificia Universidad Javeriana de Bogotá.

CEPAL, (2011). Informe Panorama Social de América Latina 2011. Página 47. Consultado 30/05/12. Disponible en página web:

http://www.eclac.cl/publicaciones/xml/1/45171/PSE2011-Panorama-Social-deAmerica-Latina.pdf

------ (2010). Informe Equidad, desarrollo y ciudadanía. Consultado el 6/8/2012. Disponible en: http://www.eclac.org/publicaciones/xml/5/4425/lcg2071.pdf

Chamuceiro, Irma. (2004). "Metáforas políticas en el discurso de dos líderes venezolanos: Hugo Chávez y Enrique Mendoza". En $\underline{A L E D, \text { Revista Latinoamericana de }}$ Estudios del Discursos. Vol: 4 Nro: 2. Pp. 91-113. 
Chayanov, A. (1974). La organización de la unidad económica campesina. Nueva Visión: Buenos Aires.

Chirico, Ma. Magdalena (1987). "El proyecto autoritario y la prensa para la mujer: un ejemplo de discurso intermediario". En El discurso político: lenguajes y acontecimientos, de Verón, E. et ál. Hachette: Buenos Aires. Pp. 53-85

Filgueira Carlos H. (1997). Bienestar, ciudadanía y vulnerabilidad en Latinoamérica. En Pérez Baldotano A. (editor) en Globalización, ciudadanía y política social en América Latina: tensiones y contradicciones. Ed. Nueva Sociedad: Caracas, Venezuela. Pp. 123147.

García Guerreiro, L. et ál. (2009). "Esta agricultura me suena familiar. Contextualizando el debate en torno a la agricultura familiar", ponencia presentada en: $\checkmark$ Congreso Argentino y Latinoamericano de Antropología Rural. Organizado por el Instituto Nacional de Tecnología Agropecuaria y el Núcleo Argentino de Antropología Rural. Ciudad de Mar del Plata, del 25 al 27 de marzo de 2009.

Garretón, M. A. (2006). "Sociedad civil y ciudadanía en la problemática latinoamericana actual", en I. Cheresky comp, Ciudadanía, sociedad civil y participación política, Buenos Aires: Miño y Dávila. Pp. 45-57

Grünfeld y Rodríguez Morcelle (2003). "El Asociativismo hoy". Ponencia presentada en el Seminario de Economía Social. Organizado por el Instituto de Estudios y Formación de la CTA.

Habermas, J. (1999) La inclusión del otro. Estudios de teoría política. Paidós: Barcelona.

(1998). Facticidad y validez. Sobre el derecho y el Estado democrático de derecho en términos de teoría del discurso. Trotta: Valladolid.

Hopenhayn, Martin (2001). "Viejas y nuevas formas de la ciudadanía". En Revista de la CEPAL, N. ${ }^{\circ} 73$, pp. 117-118.

--------- (2006). "La concentración de la propiedad sobre los medios atenta contra la democracia comunicacional". Entrevista realizada por Orlando Villalobos Finol. Utopía y praxis latinoamericana. 33, 121- 127.

Lebus, E. (2012). "Significados de la vulnerabilidad semiótica de los pequeños y medianos productores agropecuarios del NEA", en Foschiatti, Ana María (comp.) Escenarios vulnerables del Nordeste Argentino. 1. ${ }^{a}$ ed. Resistencia: Universidad Nacional del Nordeste, 2012.

López, M. S. (2009a) Ponencia "Dimensión discursiva de la vulnerabilidad del pequeño y mediano productor rural del NEA (Nordeste Argentino). IV Coloquio de Investigadores en Estudios del Discurso-1 Jornadas Internacionales de Discurso e Interdisciplina - 1518 de abril, ALEDar. Córdoba

---(2009b). "La dimensión semiolingüística de la vulnerabilidad social" (pgs. 205-211). En Sociología y ciencias sociales: conflictos y desafíos en América Latina y el 
Caribe. El contexto y la región interrogados. Vol. 1. Ed. CES, Universidad Nacional del Nordeste (EUDENE). ISBN 978-950-656-130-7. Corrientes, Argentina.

-(2010). "Construcción discursiva del concepto de lo agrario y del escenario rural del NEA: Identidades y diferencias de un sistema complejo". Proyecto de investigación de la SGCyT-UNNE, aprobado por resolución N. ${ }^{\circ}$ 921/10, del 1./12/10, N. ${ }^{\circ}$ 2010-H016, Período: 2011-2012.

-(2012). "Discurso y vulnerabilidad semiótica", en Foschiatti, Ana María (comp.) Escenarios vulnerables del Nordeste Argentino. 1. ${ }^{a}$ ed. Resistencia: Universidad Nacional del Nordeste, 2012. Cap: VIII: "Escenarios semióticos", pp. 348-366.

Marshall, T. H. (1997). "Ciudadanía y clase obrera". En Revista Española de Investigaciones Sociológicas Reis, N. ${ }^{\circ}$ 79, año 1997. Pp. 297-344. (Edición original, 1949). Consultado el 2/05/2012 disponible en:

http://www.reis.cis.es/REIS/PDF/REIS 079 13.pdf

Mata, María C. (2005a). Comunicación, Ciudadanía y poder. Pistas para pensar su articulación. En Diálogos N. ${ }^{\circ}$ 64. Pp. 66-67.

(2005b). "Condiciones objetivas y subjetivas para el desarrollo de la ciudadanía comunicativa", en: Centro de Competencia en Comunicación para América Latina, Fundación Friedrich Ebert. 58 páginas. Consultado el 7 de mayo de 2013, disponible en: http://www.c3fes.net/docs/ciudadaniacomunicativa.pdf

(2011). "Comunicación popular: continuidades, transformaciones y desafíos", revista Oficios Terrestres N.․ 26, Facultad de Periodismo y Comunicación Social, La Plata, 2011. Consultado el 3 de mayo de 2013, disponible en: http://www.perio.unlp.edu.ar/ojs/index.php/oficiosterrestres/article/viewFile/982/1031

Marafioti, R. (2004). Recorridos Semiológicos: signos, enunciación y argumentación. Eudeba: Buenos Aires.

Menéndez-Carrión, A. (2003). "El lugar de la ciudadanía en los entornos de hoy. Una mirada desde América Latina". En publicación: Ecuador Debate, no. 58. CAAP, Centro Andino de Acción Popular, Quito, Ecuador: Abril. 2003. Acceso al texto completo: http://www.dlh.lahora.com.ec/paginas/debate/paginas/debate711.htm

Mouffe, Ch. (1999). Retorno de lo político: Comunidad, ciudadanía, pluralismo, democracia radical. Paidós: Barcelona.

Núñez López, M. (2012). “Relaciones y procesos productivos. Dimensión económica de las relaciones sociales". Cap: VIII: "Escenarios semióticos" en Foschiatti, Ana María (comp.) Escenarios vulnerables del Nordeste Argentino. 1. ${ }^{\mathrm{a}}$ ed. Resistencia: Universidad Nacional del Nordeste, 2012.

O'Donnell, G. (2004). Acerca del estado en América Latina contemporánea: diez tesis para su discusión. En La democracia en América Latina. Hacia una democracia de ciudadanos y ciudadanas. Buenos Aires: PNUD.

Oraisón, Mercedes (2010). "Individuación y participación: tensiones en la construcción de ciudadanía", en Toro, B. y Tallone, A. (coord.) Educación, Valores y 
Ciudadanía, Fundación SM: Madrid. Pp. 75-95. Consultado el 25/04/2013, disponible en: http://www.oei.es/metas2021/valoressm.pdf

Quintana, L. (2011). La construcción de la identidad de los pequeños y medianos productores rurales de Corrientes, a través del análisis de los discursos en los diarios El Litoral, El Libertador y el periódico ACCIÓN, del Instituto de Cultura Popular. Tesina en la Licenciatura en Comunicación Social, Facultad de Humanidades, Universidad Nacional del Nordeste.

Van Dijk, T. (1999). Ideología. Paidós: Barcelona.

Verón, E. (1987). "La palabra adversativa. Observaciones sobre la enunciación política". En El discurso político. Lenguajes y acontecimientos. Ed. Hachette: Buenos Aires. Pp. 11-26.

Wodak, R. y Meyer, M. (2003) Métodos de análisis crítico del discurso. Barcelona: Gedisa. Año 2003.

Young, Iris M. (1989). "Polity and Group Difference: A Critique of the Ideal of Universal Citizenship", en revista Ethics, n. ${ }^{\circ}$ 99, 1989, págs. 250-274. Universidad de Chicago

Recurso electrónico disponible en: http://homepage.univie.ac.at/herbert.preiss/files/Young Polity and Group Difference A Critique of the Ideal of Universal Citizenship.pdf 